2020-04-16

\title{
A qualitative investigation of flow experience in group creativity
}

\author{
ucznik, Klara
}

http://hdl.handle.net/10026.1/15611

10.1080/14647893.2020.1746259

Research in Dance Education

Informa UK Limited

All content in PEARL is protected by copyright law. Author manuscripts are made available in accordance with publisher policies. Please cite only the published version using the details provided on the item record or document. In the absence of an open licence (e.g. Creative Commons), permissions for further reuse of content should be sought from the publisher or author. 


\section{A qualitative investigation of flow experience in group creativity}

Klara Łucznik ${ }^{1}$, Jon May ${ }^{1}$, Emma Redding ${ }^{2}$

${ }^{I}$ School of Psychology, Cognition Institute, University of Plymouth, Plymouth, UK

${ }^{2}$ Dance Science, Trinity Laban Conservatoire of Music and Dance Department, London, UK

Corresponding address:

University of Plymouth, Drake Circus, PL4 8AA, Plymouth, UK

Klara.Lucznik@plymouth.ac.uk

Klara Łucznik, $\mathrm{PhD}$, is a research fellow at the University of Plymouth. In her research, she uses improvisational dance structures as a laboratory for group creativity research, focusing on the role of attention, imagery and group dynamics.

Jon May is a Professor of Psychology at the University of Plymouth School of Psychology. He researches the role that mental representation and imagery play in decision making and motivation in all aspects of behaviour.

Emma Redding is a Professor of Dance Science at Trinity Laban Conservatoire of Music and Dance. She develops dance science as a recognised field of study that combines a range of scientific disciplines into a flexible framework for dance practice. 


\section{A qualitative investigation of flow experience in group creativity}

The role of flow experience in a group creativity task, contemporary dance improvisation, was explored through qualitative content analysis. Our focus was upon the creative process itself, rather than upon creative outcomes. Six dancers took part in an improvisation workshop, reflecting on their creative practice and any associated flow. We conducted individual semi-structured interviews with all participants supported by a video-cued recall of experience from the workshop. We interpreted their responses using qualitative content analysis. Effortless attention and enjoyment were predominant themes that emerged from the dancers' reports while describing flow. When experienced in collaboration, flow was described as 'becoming one with the group'. Dancers commonly associated flow with a highly creative state where they tended to find surprising, very 'organic and natural' movement solutions. Moreover, flow and group settings facilitated creativity through maintaining a desired creative focus for longer, lowering self-judgment and inspiring novel solutions. While findings concerning movement may be specific to dance, others are more generic to the process of group creativity. Our results confirm previous findings that associated flow with a state in which the person feels simultaneously cognitively efficient, motivated, and happy, and that these states can be facilitated in groups characterised by trust.

Keywords: flow, group flow, creativity, improvisation, dance

\section{Introduction}

Most creators (artists, engineers or scientists - irrespective of their field) claim that their most enjoyable experience resembles a process of discovery (Csikszentmihalyi, 1996, 108). Usually, the creative process begins with a problem to solve (Sawyer 2012; Lubart 2018). Typically, it is a challenging, sometimes even risky, goal to achieve, demanding skills from the creator (Reiter-Palmon 2011). Creative people develop strategies to ignore external distractions so that they may lose themselves in the creative process; they tend to forget about time and their surroundings and place the joy of working above any extrinsic rewards (Csikszentmihalyi 1996). These characteristics of the 
creative process have been identified as indicators of flow experience (Csikszentmihalyi 1988a). In domains such as music, theatre, drawing, and problem-solving, experiencing flow has been linked to better creativity outcomes (Carney, 1986; Cseh, Phillips \& Pearson, 2015; Csikszentmihalyi, 1988c, Finke \& Slayton, 1988). In dance, when reflecting on their creative process, dancers frequently referred to the experience of 'being in the flow', in particular in improvisational setting (Douse, 2015, Paskevska, 2001), but the features and the role of flow for their creative practice have not been assessed yet. In this paper we explore the flow in dance improvisation (Carter 2000; De Spain 2014; Midgelow 2019), a creative activity which is often performed in groups (Benjamin 2002; Foster 2003; Łucznik 2015); and in an observable setting, making it amenable to investigation (Sawyer 2000). In particular, we ask how dancers experience flow, how it supports their creative practice, and how being in a group affects the flow experience.

\section{Creative flow}

Flow refers to the autotelic experience, the state in which a person becomes fully absorbed and experiences feelings of energised focus, deep involvement, and success in the process of doing things (Csikszentmihalyi, 1990). Csikszentmihalyi $(1975,1997)$ formulated flow theory in terms of the balance between challenges and skills. Flow is experienced in those activities where the challenges, goals or demands of an activity meet personal skill, or action capabilities. To become fully immersed in an activity, and therefore experience flow, one needs to have clear goals and unambiguous feedback about performance (Csikszentmihalyi, 2002, 56). For example, in a game or sport, the rules define the achievements, so players know precisely what their objectives are, such as returning the ball or scoring a goal. However, in creative tasks, goals are usually more ambiguous and vague. A person must develop a strong personal sense of what 
they intend to do and internal criteria for 'good' or 'bad', so they can navigate a process (Csikszentmihalyi, 1996, p.116). Usually they originate from ones' own assessment of progress, but also might be external, coming, for example, from other co-participants, from other musicians participating in a jam session, or from an audience (Csikszentmihalyi 2014).

One of the most frequently mentioned characteristics of the flow experience is a full concentration on the present moment and the task at hand (Csikszentmihalyi, 1990, p.58). In such periods, a person forgets about all other things and, in particular, those aspects of life which are troublesome or worrying. With such a focus, only the activityrelated information enters into awareness. Consequently, one's consciousness is no longer intruded upon by the usual preoccupations of everyday life and the resultant activity becomes spontaneous, almost automatic, and effortless (Csikszentmihalyi 1988a). Flow is characterised by concentration on the task at hand, action and awareness merging, loss of self-consciousness, a sense of control, a transformation of time, and intrinsic reward (Csikszentmihalyi 1988a; Jackson 1995; Massimini and Carli 1988). Experiencing flow is itself rewarding and enjoyable (hence autotelic), and was found to be the main motivation for engaging in activities such as games, creative tasks, sport, and rituals (Csikszentmihalyi, 1990).

Csikszentmihalyi (1988c) argued that such autotelic nature and associated intrinsic motivation are central aspects of experiencing flow. Although extensive studies concentrate on performance benefits of being in the flow (Bryce and Haworth 2002; Carli, Fave, and Massimini 1988; Csikszentmihalyi 2002; Demerouti 2006; Jackson 1992; 1995; Mayers 1978), Csikszentmihalyi treated performance benefits rather as a secondary effect of flow because in any activity, performance improves when the activity provides intrinsic rewards. Thus, he suggested, flow plays a vital role in 
innovation and creativity, as all such processes require high intrinsic motivation to break through to a new level of complexity of thoughts and ideas, while the social environment rarely provides sufficient extrinsic rewards to motivate people to extensive creative work (Csikszentmihalyi 1988b). Studies in fine art found that artists who had intrinsic motivation and found their rewards in the making of art itself were more likely to maintain a creative practice in the long term (Carney 1986). Cseh, Phillips and Pearson (2015) suggested that flow provided a protective barrier against fatigue in task performance as they found that flow improved positive affect and maintained its level during the creative task. Moreover, they showed that flow was highly correlated with self-rated creativity but not with $3^{\text {rd }}$ person creativity ratings or objective external measures of productivity.

Most flow research focuses on the individual experience of flow, yet many flow activities, especially creative ones, have a primarily social character: improvised music jams, dancing, team-working, sport (Sawyer 2003; Walker 2010). Even in the wellorganised, task-oriented environment of work, Csikszentmihalyi $(1975,146)$ found that the most common place people experienced flow was in conversation with others. Moreover, such informal chats were found to be a source of creative, innovative ideas (Sawyer, 2007, p.53). Thus, group flow experience becomes central in group creativity research.

Sawyer (2007) described group flow as a collective state of mind that is experienced by an improvising group. Group flow theory, similarly in phenomenology to the individual flow experience introduced by Csikszenmihalyi (1975), describes a set of conditions and characteristics of the group's optimal, highly creative state: a common group goal and complete concentration of the group on the activity; good communication and listening skills; members' autonomy, competence, mutual 
connections and equal participation in the creation; blending egos of participants; familiarity with each other; an ability to build on the ideas of others; and finally, the potential for failure of the project, that means an activity takes place outside 'safe boundaries'(Sawyer 2007). Group flow is a typical component of group peak performance, and highly successful and creative groups seem to achieve the best results (in terms of creativity, performance and productivity) while they reach group flow (Sawyer 2003, 167). As a creative process in dance might involve both, individual and group practices, we decided to investigate flow in dance from both perspectives, reflecting on the roles of others for a dancer's individual flow experience and their creative practice.

\section{Flow in dance}

Previous research has mostly focused on the link between flow and dancers' performance rather than creative practice. Hendin and Csikszentmihalyi (1975), studying rock dancing, a social dance form of the late 1960s, showed that dancers in flow presented better performance in improvisational problem finding and solving and presented a significantly closer balance between their skills and the challenges of dance, mostly due to their possessing higher skills. Hefferon and Ollis (2006) identified factors influencing dancers' flow experience in professional performing practice: autotelic experience, challenge vs. skills balance and absorption with a task. Further, they described facilitators and inhibitors of flow, such as the importance of self-confidence, familiarity with movement material, the role of ritualistic preparation, and routine. An unfamiliar setting, for example, a new stage during a tour, was found to be the main barrier for flow to appear. In a similar context, Jeong (2012) found that imagery plays a significant role in experiencing flow, both in rehearsal and stage settings: he created, and successfully tested, an imagery-based intervention to enhance dancers' flow 
experience on stage, based on self-confidence and positive thoughts. Such intervention indeed enhanced the flow experiences of dancers, reduced anxiety, and improved their performance.

Focusing on creative practice and dance pedagogy, Paskevska (2001) argued that flow in dance is achieved through mastering a technique to be able to perform it without overt conscious control of decisions or judgement of actions. In her view, flow has a crucial importance in creative practice, and being in the flow allows dancers a free expression of their embodied ideas, even if the intellectual process of making dance

plays a significant role in the conceptualization of ideas too. She emphasised that to find a truly creative state, both technical excellence and flow are equally important: technical excellence allows a dancer to fully express and embody their ideas; while a no-mind flow state gives access to innate creativity.

\section{Improvisation as a laboratory for creativity}

Drawing on Paskevska's (2001) idea, we aim to investigate the nature of flow experience in creative practice of dance improvisation. Improvisation is not a particular style but an approach, a practice process that guide the way of working (Midgelow 2019). It focuses on the process of creating and/or choosing movements as doing them (De Spain 2014, 5), giving dancers a chance to explore movement beyond habitual patterns and to discover unknown possibilities and bodily solutions (Forsythe \& Haffner, 2012).

The nature of creativity in improvisation is very dynamic: the solution for given problems may occur while listening to the score (task), or may be discovered through the dance, or even appear later after the improvisation is finished. Typically, the recognition of 'Aha!' moments in creatively successful, well-formed improvisation 
pieces comes with the movement rather than as a prediscovered idea (Blom \& Chaplin, 1988, p.9). Consistent with the observation that movement exploration is as important as the thinking process in improvisation (Sheets-Johnstone 1981), new ideas come through dancing. In group improvisation, dancers make the most of shared choices (of movement, use of space and timing) without any previous agreement or verbal communication (Blom and Chaplin 1988, 5; Łucznik 2015). Therefore, group improvisation is fundamentally collaborative, as it places group processes in the centre of practice (Foster, 2003). In is also worth to note that dance improvisation is an essential strategy in various choreographic approaches (DeLahunta et al., 2012; Forsythe, 2012; McKechnie, 2007) and that dancers' strategies while improvising highly resemble choreographic creative thinking (De Spain, 2014; Nakano \& Okada, 2012).

Sawyer's (2000) argues that improvisation has several advantages while studying creativity. First, there is no distinction between creative process and creative product, the creative process of improvisation is the product, so the audience (or researcher) is watching the creative act as it occurs. Further, improvisation is the moment-to-moment practice, in which all decisions and choices are made spontaneously, therefore the entire creative process is observed onstage. Second, many of the improvisational approaches in different genres, including dance, are fundamentally collaborative; observing collaboration within the task on stage is relatively straightforward compared to the challenges of following other forms of creative collaboration, such as choreographic production (Grove, Stevens, and McKechnie 2005; Waterhouse, Watts, and Bläsing 2014).

In this study we use a qualitative approach, a workshop followed by interviews, to identify the cognitive and emotional markers of flow experience in dance 
improvisation and its role in the creative process. Having in mind that creativity is usually a social process (Csikszentmihalyi, 1975, 146; Sawyer, 2007) we also investigate the role of others-the group-for experiencing flow.

\section{Methods}

\section{Study design}

To capture the role of flow experience in creative dance practice, we invited dancers to take a part in an improvisation workshop led by a co-author of this article (KŁ) who is also a dance improviser. The participants engaged with several tasks and then had an opportunity to reflect on their experience of the creative process during group improvisation and any associated flow experience, using a video-stimulated recall method and group discussion. In the following week, dancers' experiences were elicited in individual interviews. All participants took part in an interview, providing the opportunity to capture multiple individual perspectives of the same group experience. To analyse collected material, we adapted qualitative content analysis. The method is based on extracting relevant information and processing it in relation to prior theory, keeping open possibilities for new insights and developments.

\section{Ethical considerations}

Ethical approval for the research was obtained from the University of Plymouth ethical approval committee, and all procedures complied with the guidelines of the APA and BPS. The participants were informed about the aims of the study, procedure and their rights beforehand. We grounded their consent for participation and collecting data. All personal data were anonymised and appropriately stored; participants had a right to withdraw before this process was finished. 


\section{Participants}

We conducted the study with the students of the one-year professional programme at a dance conservatoire based in England. This programme is based on a professional development model, providing opportunities for dancers who have taken an unconventional route or have trained outside of formal education to study in a conservatoire environment. Core elements of contemporary dance practice are complemented by range of practices and perspectives across technical, creative and performance disciplines in form of taught dance classes, creative workshops, lectureseminar based study and independent and collaborative projects. Thus, many of the students had already established their own artistic practice and they present a variety of backgrounds and artistic interests.

After an information meeting that presented the aims and general structure of the study to the students, we recruited six dancers ( 4 females, 2 males, ages between 22 and 28, $\mathrm{M}=24.2$ ). The participants had been on the same programme for 30 weeks, and were regularly sharing dance and creative practice as part of the curriculum. Each participant received $£ 16$ (an equivalent of living wage, in line with institutional research ethics policy) for taking part in a 1.5 hours group workshop session followed by a $25-40$ minutes individual interview.

\section{Materials}

Improvisation Workshop: A workshop session started with a 10-minutes group warm-up using walking exercises, changes in task focus, sense and group awareness building and finally a 'freezing game', where the group searches for common pauses (freezes) of movement and common beginnings of dancing again. Further, the dancers were asked to perform together three improvisational 
scores (Appendix 1), chosen to explore commonly used improvisational practices and give participants a range of experiences: sense awareness practice (Benjamin 2002), multisensorial imagery score (Tufnell and Crickmay 2004), and open-score with time frame (Blom and Chaplin 1988). The scores were used here, similarly to Millard (2012) understanding, as a starting point of a shared creative process, to support dancers in their improvisational exploration, in the process of not knowing, but not to determine dancers' movement or aesthetic choices. First, a 'sense awareness' score asked dancers for 'here and now' awareness, and for taking inspiration from their surroundings. Next, an openscore simply provided a time frame for movement, as no additional instruction was given. Finally, an imagery score gave dancers multimodal imagery as a starting point for improvisation. The movement vocabulary was not specified, the physical contact was not encouraged or excluded; and all scores were performed without music.

Video-cued recall of experience: After each task had been performed, the dancers individually (and simultaneously) watched a recording of their group's performance on a tablet device and commented on their creative process and flow experience in the just finished score. They were asked to reflect on their improvisational process and identify 'being in the zone', flow moments. We used this method again during individual interviews with dancers. This method showed a potential for studies into cognitive strategies, behaviour and learning processes, especially in a complex, interactive context, characterised by novelty or uncertainty and non-deliberative behaviour (Lyle, 2003); leads to an accurate recollection of an experience without requiring elaborate writing skills or high commitment from participants (Rowe, 2009). The method and associated 
software are described in Łucznik, Loesche, Redding and May (in preparation) and Łucznik and Loesche (2017).

Semi-structured interviews: We used a semi-structured approach to interviewing to support knowledge-producing potentials of dialogues by allowing a flexible development of the interview based on interviewee reactions, engagement, and subjective importance of topics (Brinkmann 2013). Each interview (Appendix 2) started by establishing how the dancer understood and described the flow experience in their own words. To facilitate the recollection of experience, we asked each dancer to choose one of the three previously performed scores at the testing session as an example. While watching the video, they were asked to reflect on the links between flow, their feeling and focus of attention and later, the role of others and group in flow experience. They were asked to discuss the relationship between flow and creativity, interaction between novel versus habitual movement solutions, and the role of flow in the creative process. Finally, participants were asked if they recognised any general moments or practices in which they usually experienced 'being in the zone' (in flow), to see if it is an experience specific to dance practice or whether it is more common in their everyday life. All interviews lasted between 25 and 40 minutes, were voice-recorded and were transcribed with NVivo software for data analysis.

\section{Analysis strategy: Qualitative content analysis}

We used the qualitative content analysis (QCA, Gläser \& Laudel, 2013) approach to structure and extract relevant material from transcribed interviews. This approach allows one to understand the phenomenon of the flow experience from multiple perspectives and explore its shared, group character. The core idea of QCA is the extraction of information from the original text and its separate processing. The process 
of analysis starts with the development of a set of categories that are then applied to the materials. Initially, the set of categories is derived from a theoretical background, however it can still be modified in number (new categories can be added), structure (dimensions) and the possible nominal values. As a result, new data are interpreted with regard to theoretical background and previous data.

Our conceptual approach was based on three general themes around the phenomenon of flow, which we used as categories for primary coding. The initial theme, 'cognitive and affective markers of flow experience', originating from Csikszentmihalyi's (1975) theory of flow, described an individual flow experience and its cognitive components. A second theme, 'the role of group', grounded in Sawyer's (2007) group flow theory, described the properties of a group that supports a participant's flow experience. Finally, the third exploratory theme, 'creative flow', summarised the dancers' remarks regarding the role of flow in creative practice, describing the use, recollection and novelty of the 'being in the flow' movement material. In each theme, the additional categories were derived inductively from the data, paying attention to the specificity of dance practice. Finally, through the analysis process, we revised and merged initial categories, and added new ones emerging from data.

The credibility of QCA is dependent upon the trustworthiness (Lincoln \& Guba, 1985) of the qualitative inquiry. We used the Elo's et al. (2014) guidelines for improving trustworthiness in each stage of investigation - preparation, organisation of content and reporting. In the preparation phase, we ensured the adequate selection of the data by including dancers during their professional training, meaning they were engaged in creative practice on a daily basis. Moreover, the workshop provided them with a specific opportunity to reflect on experiencing flow in their creative practice. In the 
organisation phase, trustworthiness assesses the quality of coding. We used theorydriven initial categories and merged them into the final ones based on whether copresence appeared in the dancers' remarks. As all data were analysed by one researcher (KŁ), the credibility of the analysis was confirmed by checking for representativeness of the data as a whole (Thomas \& Magilvy, 2011): after the process of selecting and merging data-driven categories, the final categories had to be representative across the sample (in reports of three or more dancers). In the reporting phase, trustworthiness was addressed in three ways. First, the structure of this section reflected the theoretical basis of the analysis and referred findings and emergent categories to the predicted ones, confirming the theoretical model of the phenomenon (Elo et al., 2014). Second, the included quotations reflected the participants' voice confirming that the data was accurately represented in the analysis (Lincoln \& Guba, 1985). Finally, the analysis referred to other studies on the phenomenon of flow, confirming the credibility of the findings (Graneheim \& Lundman, 2004).

\section{Results}

All dancers were familiar with a concept of flow, and they found it to be a vital component of their practice. They commonly perceived flow experience as a state when movement creation happens very naturally, in an effortless way.

\footnotetext{
Dancer F:

'It is where it just feels completely natural. There is no question, it just comes and comes, and as long as my mind does not go, 'Oh, what am I doing? Oh, what was that?' or is affected negatively by other things around me-it could be the space, other people or thoughts in my head that has nothing to do with what I am doing now-then I am in flow.'
} 
They all associated flow with positive emotions, feeling good and not being bothered with random thoughts or self-judgment. The issue of self-judgment appeared frequently in interviews, being identified as one of the major obstacles to creativity and improvisation. The role of flow experience in the creative process varied depending on a dancer's practice, especially on the level of engagement with improvisation. Dancers with extensive improvisation practice, both as performers or in generating material, context-identified flow as a highly creative state.

The following section will be divided into three parts, reflecting the analysis strategy. The first part will focus on the characteristics of individual flow experience in dance practice. In the second, the role of a group for experiencing flow will be discussed. The final part will focus on flow experience in the creative process of dancers.

\section{Cognitive and emotional markers of flow}

Most of the elements of flow experience previously described by Csikszentmihalyi (1975) were found in dancers' transcripts. Two main dimensions, of effortless attention in activity and enjoyment, emerged as the most significant. Conversely, dancers never referred to challenge versus skills balance or a need for unambiguous feedback, two requirements for flow predominant in sport and achieving peak performance activities (like performing a technically demanding ballet). There were also no direct comments on the time transformation aspect.

\section{Effortless attention}

The leading theme that emerged from transcripts was that while being in the flow, dancers merged their awareness with their movement creation: in other words, they were thinking, creating fully through moving, rather than observing their actions then 
preplanning the next ones.

\title{
Dancer A
}

'Flow is when I dance and everything that happens in movement happens naturally.

That I do not need to think a few steps ahead: 'Now I do this or that."

Dancer C

'Flow experience for me, I feel like the movement comes to me, that I do not have to make decisions like 'now I move my arm, I move over there'. I feel like it is happening to me. I can have thoughts about the thing. I would like to go on floor, but it is not like I have to decide now.'

The attention-awareness merging characteristic of flow describes an experience of loss of the sense of self, in separation from the activity and feeling of union with surroundings (Csikszentmihalyi, 1990, 63). With such a concentration on the task, dancers can fully engage with a non-propositional way of creating through their bodily responses rather than pre-planning movements that might lead them to new, novel movement solutions (Kirsh, 2011a).

To reach such a state, a person has to be fully concentrated on the task or, rather, not be bothered by any distractions. Dancers reported that interference both from the external environment as well as internal thinking were common obstacles for reaching and maintaining flow.

\author{
Dancer E \\ 'Instead of realising that I am in flow, I more realise when I am not: when my brain \\ is busy when I am thinking about the stuff, and I finish the improvisation thinking \\ that it was nonsense.'
}

In particular, self-judgment appeared as highly problematic for dancers:

Dancer B

'Because, normally, sometimes when you dance, and you do not have that flow, 
you overthink too much and instead of doing the movement you start to make a movement, so you struggle with it and it does not fit well.'

Dancers shared that they frequently critiqued their movement ideas and performance, how it might look from the outside, and how novel the idea is. While critical thinking is a vital part of dance study and creative practice, self-judgment might be limiting the creative process, stopping an artist from experimentation. What was surprising was that most of the dancers ( 5 out of 6 ) stated that they prefer to work and improvise within a group compared to improvising on their own, as with other people around, especially when they are engaged in the same activity, they self-critique less.

In summary, the dimension of effortless attention included such phenomenological markers of flow, described originally by Csikszentmihalyi (1988a), as full concentration on the task, action-awareness merging, loss of self-consciousness, and sense of control during the activity.

\title{
Enjoyment
}

Being in the flow simply feels good. All dancers referred to positive emotions associated with the flow:

\author{
Dancer C \\ 'It is a good feeling; I really enjoy it. It creates in a way more space for me; I feel \\ free.' \\ Dancer A \\ 'Happiness, joy; and I do not care anymore what other people might think about \\ what I look like. So, it feels like flying. I feel very light.'
}

Similarly to Hefferon and Ollis's (2006) study on flow experience in dance performance, dancers perceived flow as an autotelic experience. They were commonly looking for being in flow while improvising. Moreover, they highly valued full 
engagement with actions that eventually led them into flow, in comparison to a more analytical external way of composing their movement. As Csikszentmihalyi (1996, p.120) stated, 'many of the peculiarities attributed to the creative persons are really just ways to protect the focus of concentration so that they may lose themselves in the creative process', as distractions usually interrupt flow and the creative work. In conclusion, the dimension of enjoyment combines affective aspects of flow: positive emotion, intrinsic reward and optimal experience.

Dancers highly valued the flow moments in improvisation as 'good bits' and as aesthetically appealing (see 'Creative flow' section below). In improvisation, the criteria of success are rather ambiguous: the practice contains a basic, culturally defined set of rules but their character is rather ephemeral (Sawyer 2000). In this context, the enjoyment that accompanied flow experience provided dancers with primary feedback about their performance.

\section{The role of group for experiencing flow}

Dancers reported that entering and maintaining the flow state was easier while being in the group compared to being on their own, however the quality of the group, familiarity with others and levels of trust also mattered. Sawyer's properties of group flow were reflected in dancers' reports, merging into two main themes: becoming one with the group and trust. An additional theme, the role of touch in flow experience, also emerged.

\section{Becoming one with the group}

Becoming one with the group was the predominant characteristic of flow in group improvisation. In their reports, dancers referred to the point where all actions or decisions were shared and the feeling of deep connection with others appeared. 


\section{Dancer B}

'Then the flow came when we were all like, even if it was not necessary contact like touching, but just being in relation, moving in relation to each other and just with other people instead of individuals moving alone in the same space.'

Dancer C

'I feel [flow] if with group I am in (...), we have something in common; we are on the same page. We are not doing completely different things. It could be different dynamics, but there is some energy.'

Similarly, in studies on jazz music ensembles and improvised theatre, Sawyer (2003, s.44) noticed that in group flow the performers were in interactional synchrony and their action seemed to come naturally. Each of the group members shared that they were able to anticipate fellow performers' actions before they even happened. Later, describing the phenomena of blending egos, Sawyer (2007) suggested that group flow happens when the group comes together, is in sync and the performers seem to be thinking with one mind.

Further, dancers reported that being in the group enriched their choices, as they had the opportunity to get inspired or develop movement from what emerged in the group. The ability of parallel processing-creating and making choices while closely listening to other members and immediately responding to their action-was placed as one of main requirements for group flow to happen (Sawyers 2003, p.44). The ability to build on others' ideas is considered a learned skill that requires previous, extensive training and warm-up for the group to establish peak performance (Sawyers, 2007). However, dancers commonly reported that in the improvisational process, having other people to work with made the creative process easier to maintain and more fruitful compared to their solo creation.

\section{Dancer F}

'The most enjoyable part of dance improvisation with other people is when it 
works: you are keeping your own integrity while your movement is being, and your thought process are being, enriched by other people around you.'

Dance training includes opportunities for dancers to develop their non-verbal communication skill, spatial and sound awareness as a substantial part of practice is taught with rather limited verbal explanation, through demonstration, mimicking actions and mirroring, with an emphasis on coordinated movement of groups. Such training naturally prepares dancers for group interactions and group creative processes.

In summary, becoming one with the group dimension merged aspects of Sawyer's (2007) group flow characteristics such as mutual connections, good communication and listening skills, and the ability to build on the ideas of others.

Trust

While talking about conditions and obstacles to getting into flow, dancers referred to familiarity with others and trust within the group. Feeling safe and accepted is essential for improvisation and creativity, as those practices require dancers to experiment and publicly act outside of their familiar schemas.

\section{Dancer C}

'I like if there is the environment for trust. Then I can experiment more and I enjoy

it more.'

Dancer D

'When I dance with someone I do not know, I have no idea who they are, probably I feel they are watching me all the time, they would judge me.'

Sawyer (2003) suggested that familiarity with each other's expression and communication style helps group members to respond quickly and accurately and builds shared understanding of the group's goals and roles. As noted previously in this study, it 
also helps to lower dancers' self-judgment, a primary obstacle for creativity and getting into flow.

To summarise, dancers found it very useful to work in a group as they were less critical about themselves and they had to give up on controlling the situation.

\author{
Dancer A \\ 'It is easier to drop this thing that I am being watched. Because, I know, if someone \\ is watching I am not the only person who is watched and might be judged.' \\ Dancer C \\ 'A group helps, because I accept that I cannot control everything. So people around \\ me will do things, they could be in my way and then I have to move. The \\ acceptance that I cannot decide everything anyway helps me to not evaluate too \\ much what I do. It makes me bit more relaxed - not thinking too much.'
}

The last response reflected also the other characteristic of group flow: the potential of failure. Even if there are no explicit parameters of successful improvisations, dancers tend to judge their performance a lot. Improvisation, because of its nature, allows dancers to act on the edge of their abilities of creativity, performance technique and communication skills in the group. This keeps practice vivid and, for the most part, challenging over time.

Group flow is an emergent property that allows group members to engage in actions that they would not have thought of without the inspiration of the group (Sawyers, 2003, s.45). In many ways, through creative proposals, acceptance and support of one's ideas, group flow helps individuals to attain their own flow state. Most participants in this study ( 5 of 6 dancers) confirmed that they were more likely to experience flow while being in a group. Safe setting and a certain level of trust between group members were required for the group to succeed. Although group familiarity is one of the original aspects of group flow experience (Sawyer, 2007), the emphasis on trust in the present study is novel. 


\section{Touch}

A dimension of touch was not predicted in the initial categories, it emerged directly from the analysis of interviews. Dancers expressed that being in physical contact with others was one of the triggers for flow experience. In this regard, contact improvisation (improvisation that involves physical contact between dancers) requires focussed attention on body sensations in order to maintain contact with the other and sustain one's own integrity over time. Some dancers found this kind of attention to entail a state of flow.

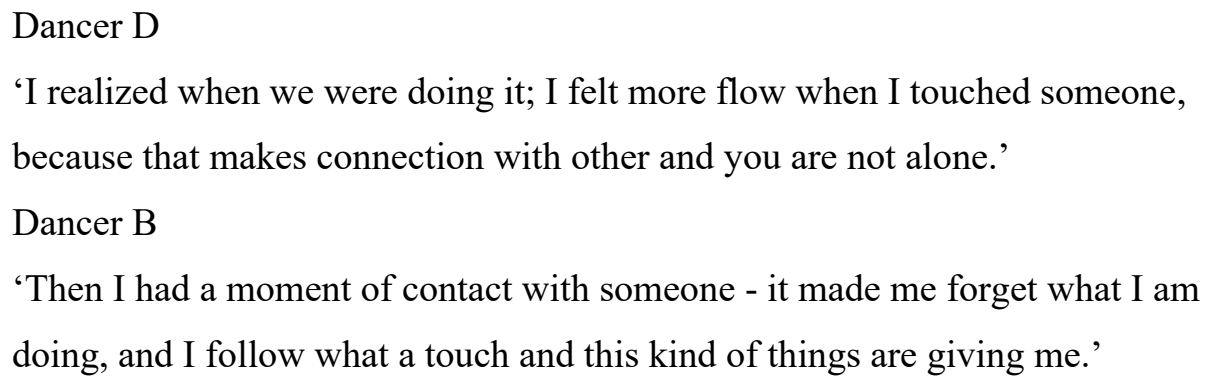

Contact Improvisation is based on the principles of maintaining 'the point of contact' in duet form and an on-going investigation of movement patterns through sensing, feeling and noticing bodily changes (Bull, 1997). Little (2014) considers contact improvisation to be a form of the active sensing process, where the attention is shared between dancers with the aim of supporting shared complex actions. Responding to tactile information demands huge attention. In contact improvisation, most of the communication between partners happens through sensing, touch and shifts in proprioception, while vision and auditory signals are usually diminished. Such shifts might promote flow experience through a more sustained focus of dancers' attention on shared embodied tasks. 
One dancer highlighted that the quality of the relationship is very important and that being in physical contact when understanding and collaboration is poor can be very distracting.

\section{Responded C}

'When I work in physical contact with another, if that is the task and I know I have to be with this person, it could disturb the flow experience if it does not run smoothly, and I get this more, considering again more thinking how can I solve it, what do we do know, what she or he wants.'

This example further emphasizes the importance of listening and communication skills for successful collaboration.

\section{Creative flow}

The last, explorative section of analysis summarised dancers' remarks regarding the role of flow in their creative practice. The findings are summarized around three emerging categories: outcomes of creative flow, flow as a state of mind and quality of movement, and recollection of flow material.

\section{Outcomes of creative flow}

While reflecting on the benefits of being in flow, dancers commonly commented that it was a highly creative state when they could surprise themselves with unusual movement solutions.

\section{Dancer B}

'I can surprise myself, I can find myself in the places like, I do not know how I get here and I do not necessarily know how to get out of there.'

Being novel was connected to looking for solutions through 'body-thinking'; solving problems in a non-propositional way in which the reflective processes and 
explicit knowledge were limited through full attention on the dance and body. Dancers highly valued this approach to movement creation, finding those solutions as more organic and 'natural' than one that originated from choreographic or technique knowledge.

\author{
Dancer F \\ 'I think that if you are uninterrupted and you are in that moment, the movement \\ you create is going to be interesting one way or another, because there will be no \\ breaks in what is coming out. And that means you can push it. And the longer you \\ can stay in that state the more experimental you can be without bringing your \\ thinking and your knowledge about technique to it. That could make it more \\ complicated or more interesting, but less organic in the way that is coming \\ together.'
}

\title{
Flow as a state of mind and quality of movement
}

It is important to mention that flow in dance practice also describes a particular quality of movement, defined by Rudolf Laban (Newlove and Dalby 2004) as one of the efforts of his effort theory, a dynamic factor of movement that is unimpeded or continuous such as hair floating in water or the passage of water in response to gravity. When utilizing flow quality, one body part follows another carrying the dynamic and there are no breaks or pauses in the movement. A similar description of flow movement was reported in this study.

\section{Dancer B}

'(...) movements that are quite flow in the body, like wavy movements, that never really stop, and one movement just leads to another one to another one... It would be not jumps. It is something continuous, not that the speed is always the same, it could go faster and slower, but just continues, that the movement never stops.' Dancer E

'There is a sort of way of moving with the word of flow itself. (....). You go with the way you are moving in the flow, you not doing inorganic movement (....) It is a much more fluid sense of movement in the body.' 
Dancers were commonly conscious of an association of the term 'flow' with the movement quality description. Still, they noticed that a particular, organic and fluid way of moving would promote the mental state of being in the flow. At the same time, it did not limit the movement to one, particular quality; rather the way of connecting material and solutions was found to be highly fluid.

\section{Dancer E \\ 'I am not saying that all your movement became one big fluid massive unite and you never stop moving. (...) It is the easiest way to come into that state and it makes that more interesting if you bring some more stochastic moves (...).'}

\section{Recollection of flow material}

In previous studies on combined flow in a jazz ensemble (Hart and Di Blasi 2013), it was noticed that musicians had rarely any clear memories of music material from 'being in the zone' moments. While for the purpose of improvisation as a performance practice it is not primarily important, as the improvised performance is a unique event, when using improvisation process for movement creation, lacking the memories of the most valued material might be an issue. Dancers ( 4 of 6 , all who frequently use improvisation as a part of creative process for setting movement) noticed this issue.

\section{Dancer A}

'When I'm in rich flow it is more for me, and when it is over then I regret that I did not film it. And I cannot remember. On the one hand, I want to keep it for my own, but then again, if it felt really good I want to show it to other people too.'

Dancer F

I chose to revisit the material. Obviously, you cannot recreate whole material because it is not set. What you can do (...), you remember few things that you've done that were really good for you (...). It can start from there and then develop. I do not think that it would ever be the same but it could. 
One of the common solutions was the practice of video recording improvisation sessions with the aim to capture highly creative moments and be able to recreate them. It is interesting to notice that improvisation started to become more dominant in dance creative practice alongside the availability of affordable video technology, which allowed dancers to effectively document and transform their process through the use of technology which had not been possible previously (DeLahunta 1998).

\section{Conclusion}

This paper studied the experience of flow during a group creativity task, using dance improvisation as a domain. While some of the findings with regard to movement and touch may be specific to dance, others are potentially more generic to the process of group creativity. Effortless attention and enjoyment were the most predominant themes that emerged from the dancers' reports while describing flow. Our results confirm previous findings by (Moneta and Csikszentmihalyi 1996, 227) that associated flow with 'a psychological state in which the person feels simultaneously cognitively efficient, motivated, and happy'.

Not all core characteristics of the experience of flow were present in interviews. Dancers rarely related to the 'challenge-skill balance' idea, and only one person mentioned that being successful in improvisation requires a certain level of skill. This aspect of flow is central from the conceptual point of view, as a person can experience flow only when their expertise and skills face an adequate challenge, otherwise they will experience boredom, when challenges are too low, or stress when the skills are not sufficient (Moneta and Csikszentmihalyi 1996). On the other hand, Csikszentmyhalyi (1985) introduced the term of 'emergent motivation' to describe the dynamics of an actor and environment system. He argued that flow experience is shaped in such interaction on a moment-to-moment basis. The nature of improvisation allows dancers 
to constantly regulate the situation according to their skills and modify their dance, making it more or less challenging through their movement choices. The capacity of dance improvisation to accommodate various abilities, challenges and interests is highlighted by inclusive dance practice, where disabled and non-disabled dancers successfully work together as equal creative partners, regardless of their physical abilities (Benjamin 2002, 7). The improvisational and creative settings might naturally promote flow experience, as participants self-regulate their engagement with the score, having the possibility of fitting their skill to upcoming challenges and adapt the challenges to their skill level.

The dancers interviewed did not refer directly to the 'transformation of time', the funnelling of awareness characteristic of flow, related to loss of awareness of time (Csikszentmihalyi 1990). As we conducted interviews in context of a delivered workshop, and our scores were rather short, it is possible that this topic was simply irrelevant regarding the settings. Our short scores did not provide the environment for losing time awareness; although dancers did commonly associate flow with their ability to maintain full focus on an activity for longer than usual.

Dancers also revealed that being in the flow lowered their self-critique. Previous studies gave evidence that flow experience positively influences affect within the creative process and might provide a protective barrier against usually fatiguing aspects in a task (Cseh, Phillips, and Pearson 2015; 2016). Our findings suggest that flow experience also has protective abilities regarding self-esteem and helps the creative process though limiting self-judgment.

Our findings suggest that group improvisation facilitates flow experience and the creativity of individuals through maintaining a desired creative focus for longer, lowering self-judgment and inspiring novel solutions. The positive influence of others 
on creative process was rather contradictory, as intuitively social judgment and social exposure should play a negative role in creative practice. In our case, dancers found the group to be a supportive, creative environment for their ideas to develop. Perhaps, it was due to their deep familiarly with each other and already built trust, as they had been studying together for more than half year already.

Our results support Sawyers' (2007) conditions that facilitated group flow-the optimal, peak experience in a group. Two main themes that emerged from interviews were: 'becoming one with the group' and the importance of trust between group members before and during the activity. While talking about shared experience of becoming one with the group, dancers emphasized complete, shared concentration on the task and a feeling of mutual connection with others in co-creative process of improvisation. They highlighted the importance of good communication and listening skills, an ability to build on others' ideas and get inspired by others. They stressed that trust between each other is a basis for good communication and co-creative processes of sharing ideas.

The role of trust with regard to group flow had not previously been widely discussed, however Sawyers $(2003,44)$ stated that for some groups (referring to musical ensembles and improvised theatre) a preliminary warm-up and team-building exercises were crucial to establish the group flow.

Dancers commonly associated flow with a highly creative state where they tended to find surprising, very 'organic and natural' movement solutions. It is important to emphasize that the mental state of flow did not limit their expression in the use of a particular quality of movement, but rather they found linking between various ideas to be smooth and effortless, even when moving between extremes in movement. 
Dancers reported that flow and being in the group helped them to maintain the creative process for longer, allowing exploration of novel material beyond their habitual responses. They were aware of a problem of gathering material created during the flow state, as reflective processes and memory tend to be limited, however they referred to some of the techniques they used to recollect 'flow material', such as recording improvisation, remembering general movement or creative cues, and re-enacting the improvisation.

In conclusion, flow in group creativity is characterised by effortless attention to a task and enjoyment, described as a state of 'becoming one with the group'. Dancers stated that the group would facilitate prolonged and deep engagement in a creative task and help to maintain flow for longer. However, these effects are related to the quality of collaboration and trust. Finally, dancers recognised flow as a highly creative state that allowed them to go beyond their habits and find new, yet organic embodied ideas.

Acknowledgments: This research was funded by the EU Marie Skłodowska-Curie Initial Training Network (details to add).

\section{Bibliography:}

Benjamin, Adam. 2002. Making an Entrance: Theory and Practice for Disabled and Non-Disabled Dancers. Routledge.

Blom, Lynne Anne, and L. Tarin Chaplin. 1988. The Moment Of Movement: Dance Improvisation. University of Pittsburgh Pre.

Brinkmann, Svend. 2013. Qualitative Interviewing. Oxford university press.

Bryce, Jo, and John Haworth. 2002. 'Wellbeing and Flow in Sample of Male and Female Office Workers'. Leisure Studies 21 (3-4): 249-63.

Carli, Massimo, Antonella Delle Fave, and Fausto Massimini. 1988. 'The Quality of Experience in the Flow Channels: Comparison of Italian and US Students.' In Optimal Experience: Psychological Studies of Flow in Consciousness, edited by Mihaly Csikszentmihalyi and Isabella Selega Csikszentmihalyi, 288-318. Cambridge University Press.

Carney, Jean. 1986. 'Intrinsic Motivation and Artistic Success (Unpublished Dissertation Work)'. US: University of Chicago.

Carter, Curtis L. 2000. 'Improvisation in Dance'. The Journal of Aesthetics and Art Criticism 58 (2): 181-90. 
Cseh, Genevieve M., Louise H. Phillips, and David G. Pearson. 2015. 'Flow, Affect and Visual Creativity'. Cognition and Emotion 29 (2): 281-91.

https://doi.org/10.1080/02699931.2014.913553.

. 2016. 'Mental and Perceptual Feedback in the Development of Creative Flow'.

Consciousness and Cognition 42 (May): 150-61.

https://doi.org/10.1016/j.concog.2016.03.011.

Csikszentmihalyi, Mihaly. 1988a. 'A Theoretical Model for Enjoyment'. In Beyond Boredom and Anxiety, edited by Mihaly Csikszentmihalyi, 1st ed., 35-54. San Francisco, London: Jossey-Bass Publishers.

- 1988b. 'The Future of Flow'. In Optimal Experience: Psychological Studies of Flow in Consciousness, edited by Mihaly Csikszentmihalyi and Isabella Selega Csikszentmihalyi, 364-83. Cambridge: Cambridge University Press.

1990. Flow: The Psychology of Optimal Experience. 1st ed. New York: Harper \& Row.

1996. Creativity: Flow and the Psychology of Discovery and Invention. New York: Harper Collins Publishers.

2002. Flow: The Classic Work on How to Achieve Happiness. London: Rider. 2014. 'Society, Culture, and Person: A Systems View of Creativity'. In The Systems Model of Creativity, edited by Robert Sternberg, 47-61 (Reprinted from $<$.i. $>$ Conception of Giftedness $<$./i. $>$ pp. 325-339, by R.J. Sternberg and J. E. Davisdon, Eds. 1988, Cambridge, Cambridge University Press. Dordrecht: Springer.

De Spain, Kent. 2014. Landscape of the Now: A Topography of Movement Improvisation. Oxford University Press.

DeLahunta, Scott. 1998. 'Sampling... Convergences between Dance and Technology'. In . Aarhus, Denmark. http://art.net/ dtz/scott2.html.

Demerouti, Evangelia. 2006. 'Job Characteristics, Flow, and Performance: The Moderating Role of Conscientiousness.' Journal of Occupational Health Psychology 11 (3): 266-80. https://doi.org/10.1037/1076-8998.11.3.266.

Foster, Susan Leigh. 2003. 'Taken By Surprise: Improvisation in Dance and Mind'. In Taken by Suprise: A Dance Improvisation Reader., edited by Ann Cooper and David Gere, 3-10. Middletown, Connecticut: Wesleyan University Press.

Grove, Robin, Catherine Stevens, and Shirley McKechnie. 2005. 'Thinking in Four Dimensions: Creativity and Cognition in Contemporary Dance'. Thinking in Four Dimensions: Creativity and Cognition in Contemporary Dance, vii.

Hart, E., and Z. Di Blasi. 2013. 'Combined Flow in Musical Jam Sessions: A Pilot Qualitative Study'. Psychology of Music, October. https://doi.org/10.1177/0305735613502374.

Hendin, Judy, and Mihaly Csikszentmihalyi. 1975. 'Measuring Flow Experience in Rock Dancing'. In Beyond Boredom and Anxiety, 102-22. Jossey-Bass Publishers.

Jackson, Susan A. 1992. 'Elite Athletes in Flow: The Psychology of Optimal Sport Experience'. Faculty of the Graduate School, University of North Carolina at Greensboro. 1995. 'Factors Influencing the Occurrence of Flow State in Elite Athletes'. Journal of Applied Sport Psychology 7 (2): 138-66.

Little, Nita. 2014. 'Restructuring the Self-Sensing: Attention Training in Contact Improvisation'. Journal of Dance \& Somatic Practices 6 (2): 247-260.

Lubart, Todd, ed. 2018. The Creative Process: Perspectives from Multiple Domains. London: Palgrave Macmillan UK. https://doi.org/10.1057/978-1-137-50563-7. 
Łucznik, Klara. 2015. 'Between Minds and Bodies: Some Insights about Creativity from Dance Improvisation'. Technoetic Arts 13 (3): 301-8. https://doi.org/10.1386/tear.13.3.301_1.

Massimini, Fausto, and Massimo Carli. 1988. 'The Systematic Assessment of Flow in Daily Experience.' In Optimal Experience: Psychological Studies of Flow in Consciousness, edited by Mihaly Csikszentmihalyi and Isabella Selega Csikszentmihalyi, 266-87. Cambridge: Cambridge University Press.

Mayers, Patrick L. 1978. 'Flow in Adolescence and Its Relation to School Experience.' Midgelow, Vida L. 2019. 'Introduction: Improvising Dance: A Way of Going about Things'. In The Oxford Handbook of Improvisation in Dance, 1-24. Oxford University Press.

Millard, Olivia. 2012. 'From Score to Work? Making a Group, Improvising a Dance'. Deakin University. http://dro.deakin.edu.au/eserv/DU:30061018/millardfromscore-2013A.pdf.

Moneta, Giovanni B, and Mihaly Csikszentmihalyi. 1996. 'The Effect of Perceived Challenges and Skills on the Quality of Subjective Experience'. Journal of Personality 64 (2): 275-310.

Newlove, J., and J. Dalby. 2004. Laban for All. A Nick Hern Book. Nick Hern.

Reiter-Palmon, P. 2011. 'Problem Finding'. In Encyclopedia of Creativity, edited by Steven R. Pritzker and Mark A. Runco, Second, 2:250-53. Academic Press/Elsevier.

Sawyer, Keith. 2000. 'Improvisation and the Creative Process: Dewey, Collingwood, and the Aesthetics of Spontaneity'. The Journal of Aesthetics and Art Criticism 58 (2): 149-61. https://doi.org/10.2307/432094.

- 2003. Group Creativity: Music, Theater, Collaboration. Mahwah, N.J: L. Erlbaum Associates.

- 2007. Group Genius: The Creative Power of Collaboration. Basic Books. . 2012. 'The Creative Process: Part 1'. In Explaining Creativity: The Science of Human Innovation, 87-105. Oxford University Press, USA.

Sheets-Johnstone, Maxine. 1981. 'Thinking in Movement'. The Journal of Aesthetics and Art Criticism 39 (4): 399-407.

Tufnell, Miranda, and Chris Crickmay. 2004. A Widening Field. Dance.

Walker, Charles J. 2010. 'Experiencing Flow: Is Doing It Together Better than Doing It Alone?' The Journal of Positive Psychology 5 (1): 3-11. https://doi.org/10.1080/17439760903271116.

Waterhouse, Elizabeth, Riley Watts, and Bettina E. Bläsing. 2014. 'Doing Duo - a Case Study of Entrainment in William Forsythe's Choreography "Duo"'. Frontiers in Human Neuroscience 8 (October). https://doi.org/10.3389/fnhum.2014.00812. 


\section{Appendix 1. The three improvisational tasks used in the workshop session.}

1. Sense awareness (drawn from Adam Benjamin's (2002) open-score practice)

Arrive in the space. Sense your weight... Let your eyes look around...

Let your feet sense the floor.

Let all your senses open and lead you for the next few minutes of dance.

2. Open-score (drawn from Lyne Anne Blom and L. Tarin Chaplin's (2000))

The only rule this time is the time limit... Please, enter the space,

find your way through...

and after 5 minutes I will ask you to find an ending.

3. Imagery task (inspired by variety of Miranda Tufnell and Chris Crickmay's (2004)

imagery practices and Wayne McGregor's (2013) Choreographic Thinking Tools)

Imagine the colour BLUE, you can image an object, landscape or just some substance or blue haze

how does it fill in the surrounding? What is it density?

And its texture? Its sound?

What kind of blue things comes to your mind? Place them in the space. 


\section{Appendix 2. Semi-structed interview on flow experience}

1. How would you describe a flow experience during improvisation in your words?

2. [While watching a chosen recording of improvised score]

- Where is your attention?

- How do you feel in those moments?

- Are you able to recognize this state during improvising? Or you reflect on it later?

3. Are you more likely to experience flow in individual improvisation (for example in movement research), or in group improvisation?

4. What is the role of a group, others dancers, in flow experience?

5. If you could reflect on movement material and qualities during flow, are they in any way specific?

- Familiar for you? Or, maybe surprising or unexpected?

- How do you evaluate such moments?

- Are you able to recollect that material after improvisation? For example, to use it for choreographic purpose?

6. Do you recognise some typical moments or practices when you are usually getting into flow easily? 